\title{
Níveis de energia metabolizável em rações formuladas com base no conceito de proteína ideal e suplementadas com fitase para leitões dos 15 aos $35 \mathrm{~kg}^{1}$
}

\section{Marcelo José Milagres de Almeida ${ }^{2^{*}}$, Elias Tadeu Fialho ${ }^{3}$, Márcio Gilberto Zangeronimo ${ }^{4}$, José Augusto de Freitas Lima ${ }^{3}$, Paulo Borges Rodrigues ${ }^{3}$, Hunaldo Oliveira Silva ${ }^{5}$}

\author{
${ }^{1}$ Projeto financiado pelo CNPq. \\ 2 Escola Agrotécnica Federal de Barbacena - EAFB - Barbacena, MG. \\ ${ }^{3}$ Departamento de Zootecnia da UFLA. Pesquisador Bolsista do CNPq. \\ ${ }^{4}$ Universidade José do Rosário Vellano - UNIFENAS, Alfenas, MG \\ ${ }^{5}$ Escola Agrotécnica Federal de São Cristóvão - EAFSC - Aracajú - SE.
}

RESUMO - Um experimento foi conduzido para avaliar a influência de diferentes níveis de energia metabolizável (EM) e proteína bruta $(\mathrm{PB})$ em rações formuladas segundo o conceito de proteína ideal com suplementação de fitase sobre o desempenho e as características de carcaça de leitões dos 15 aos $35 \mathrm{~kg}$. Foram utilizados 84 leitões híbridos comerciais (Agroceres $\times$ MS60) com peso médio inicial de $15,3 \mathrm{~kg}$, distribuídos em delineamento de blocos casualizados, em esquema fatorial $3 \times 2+1$, composto de três níveis de energia metabolizável (3.080, 3.230 e $3.380 \mathrm{kcal} / \mathrm{kg})$, dois de proteína bruta (14\% e $16 \%)$ e da suplementação com aminoácidos sintéticos e fitase (1.000 uft/kg de ração), por meio da redução do teor de cálcio em $25 \%$ e o de fósforo em $30 \%$. A ração controle com $18 \%$ de PB foi formulada segundo o conceito de proteína bruta e sem adição de fitase, visando atender às exigências nutricionais de leitões, totalizando sete tratamentos, cada um com seis repetições e dois animais por unidade experimental. As rações não influenciaram o ganho de peso, a conversão alimentar, o consumo de energia metabolizável e os pesos dos órgãos (tanto absoluto como relativo) dos leitões. O consumo de ração foi maior e a taxa de deposição de gordura foi menor nos leitões alimentados com rações contendo $3.080 \mathrm{kcal} \mathrm{EM/kg}$. Verificaram-se redução no consumo de nitrogênio, aumento na eficiência de utilização de nitrogênio para ganho e menor teor de uréia sanguínea nos leitões alimentados com as rações com 14\% PB em comparação àquelas com 18\%. A redução dos níveis de EM, PB, fósforo disponível (Pd) e cálcio (Ca) para $3.080 \mathrm{kcal} / \mathrm{kg}, 14 ; 0,54$ e 0,28\%, respectivamente, em rações para leitões, formuladas segundo o conceito de proteína ideal e fitase, não prejudica o desempenho de leitões dos 15 aos $35 \mathrm{~kg}$.

Palavras chave: aminoácidos, desempenho, enzima, nutrição, suínos

\section{Metabolizable energy levels in diets formulated according to the ideal protein concept and supplemented with phytase for piglets from 15 to $35 \mathrm{~kg}$}

ABSTRACT - A total of 84 barrows and females from a commercial hybrid (Agroceres $\times$ MS60), averaging $15.3 \mathrm{~kg}$, was raised from 15 to $35 \mathrm{~kg}$ to evaluate the effect of different dietary levels of metabolizable energy (ME) and crude protein (CP) formulated according to the ideal protein concept and phytase supplementation on performance and carcass characteristics. The experiment was analyzed as a complete randomized block design, in a factorial arrangement of treatments $3 \times 2+1$, with three ME levels (3,080,3,230, and 3,380 kcal/kg), two of CP (14\% and 16\%), supplemented with synthetic amino acids and $1000 \mathrm{FTU} / \mathrm{kg}$ of phytase, with calcium level reduced by $25 \%$ and phosphorus by $30 \%$. Additional control treatment was formulated with $18 \% \mathrm{CP}$ and without phytase, to attend the nutrient requirements of pigs according to Brazilian Feedstuffs Tables recommendations. Therefore, seven treatments, six replications and two animals per experimental unit were used. No treatment effect on daily weight gain, feed conversion, daily ME intake and weight of organs (absolute and relative) of pigs was observed.Feed intake was higher and fat deposition rate, lower in pigs fed diet with 3,380 kcal ME/kg. Decreasing nitrogen intake, increasing efficiency of nitrogen utilization for gain and lower blood urea content were observed for pigs fed $14 \% \mathrm{CP}$ diets compared to those with $18 \%$. The reduction of levels of ME, CP, available phosphorus and calcium to $3,080 \mathrm{kcal} / \mathrm{kg}$, $14 \%, 0.54 \%$ and $0.28 \%$, respectively, in rations for pigs, formulated based on ideal protein concept and phytase, do not affect performance of pigs from 15 to $35 \mathrm{~kg}$.

Key Words: amino acids, enzyme, nutrition, performance, swine 


\section{Introdução}

O desenvolvimento da nutrição animal por meio da utilização de conceitos modernos na formulação de rações, como o da proteína ideal, e da aplicação de novos conhecimentos relacionados ao metabolismo, à melhor avaliação nutricional dos ingredientes e à produção de aminoácidos industriais e enzimas exógenas (fitase, por exemplo) tem permitido o fornecimento de dietas mais adequadas às exigências produtivas de cada categoria animal, o que melhora a eficiência de utilização dos nutrientes dos alimentos.

A proteína, de modo geral, é um dos principais componentes dos órgãos e das estruturas do organismo animal, portanto, é necessário seu contínuo suprimento alimentar para o crescimento e a produção desejados (Pozza et al., 1999). Assim, o adequado equilíbrio aminoacídico da dieta e a biodisponibilidade dos aminoácidos é importante para assegurar o máximo crescimento dos animais. A formulação de dietas com reduzido teor de proteína e com adição de aminoácidos cristalinos tem sido associada ao melhor aproveitamento dos nutrientes e contribui, ao mesmo tempo, para reduzir a carga poluente dos dejetos produzidos pelos animais (Zangeronimo et al., 2006).

Além disso, resultados de pesquisas com o uso de fitase em rações para suínos também têm sido promissores, o que leva nutricionistas a acreditar na redução do fósforo inorgânico das rações, uma vez que a fitase age nas ligações do grupo fosfato ao ácido fítico, liberando o fósforo que faz parte desta molécula (Cromwell \& Coffey, 1991). Além de aumentar a disponibilidade do fósforo, a utilização desta enzima também melhora a disponibilidade de outros minerais, como cálcio, magnésio, cobre, ferro e zinco (Adeola et al., 1995) e, possivelmente, a dos aminoácidos (Silva et al., 2004), influenciando positivamente o desempenho dos animais.

De acordo com Curtis (1983), os animais consomem alimento de acordo com suas necessidades energéticas, ou seja, a ingestão de energia depende das necessidades de nutrientes para mantença, crescimento e formação dos produtos. Segundo Hedegus (1996), o balanço entre proteína e energia é essencial para minimizar o uso de proteína para obtenção da energia necessária ao metabolismo. Neste sentido, a limitada ingestão de energia pode ser o fator de maior restrição à deposição protéica no suíno jovem (Batterham, 1994) e isso pode ser a causa do menor desempenho dos animais em alguns experimentos utilizando o conceito de proteína ideal (Zangeronimo et al., 2006).

Apesar de os genótipos modernos responderem melhor ao aumento no consumo de energia (Rezende et al.,
2006), os efeitos de rações contendo fitase formuladas com diferentes níveis de energia metabolizável e proteína bruta para suínos na fase inicial são pouco conhecidos. Como a quantidade da energia consumida influencia a deposição de gordura na carcaça de suínos, é fundamental o conhecimento da relação entre o consumo de energia e o consumo de proteína na separação dos nutrientes para deposição de proteína e lipídios e para a elaboração de estratégias de alimentação para suínos visando ao máximo desempenho em cada fase de vida do animal.

O objetivo neste trabalho foi avaliar os efeitos da energia metabolizável e dos níveis de proteína bruta em rações formuladas segundo o conceito de proteína ideal e fitase sobre o desempenho, o peso de órgãos, os níveis de uréia no soro e as taxas de deposição de proteína e gordura na carcaça de leitões dos 15 aos $35 \mathrm{~kg}$.

\section{Material e Métodos}

O experimento foi conduzido no Setor de Suinocultura do Departamento de Zootecnia da Universidade Federal de Lavras, em Lavras, Minas Gerais. Foram utilizados 84 suínos machos castrados e fêmeas (Agroceres $\times$ MS60), com peso inicial de $15,3 \pm 1,4 \mathrm{~kg}$ (42 dias de idade e peso final de 32,5 $\pm 3,1 \mathrm{~kg}$ (73 dias de idade). Os animais foram alojados em sala de alvenaria, no galpão de creche, em baias suspensas $(2,0 \times 1,2 \mathrm{~m})$ a 1,2 $\mathrm{m}$ de altura, com piso ripado, equipadas com comedouros semi-automáticos e bebedouros do tipo chupeta, durante um período experimental de 26 dias. A temperatura foi controlada com lâmpadas para aquecimento e ventiladores, sendo registradas máxima e mínima de $19 \pm 2,5^{\circ} \mathrm{C}$ e a máxima de $25 \pm 2,4^{\circ} \mathrm{C}$.

O delineamento experimental utilizado foi o de blocos casualizados, em esquema fatorial $3 \times 2+1$, composto de três níveis de energia metabolizável (3.080, 3.230 e 3.380 $\mathrm{kcal} / \mathrm{kg}$ ), dois níveis de proteína bruta (14\% e 16\%). As rações foram suplementadas com $0,54 \%$ de cálcio $(\mathrm{Ca})$ e 0,28\% de fósforo disponível (Pd), com os aminoácidos sintéticos lisina, metionina, treonina, triptofano e valina e com a enzima fitase Nathufós ${ }^{\circledR} 10000$ (1.000 uft $/ \mathrm{kg}$ de ração). Como tratamento adicional, a ração foi formulada com base no nível de $\mathrm{PB}$, sem adição de fitase, para atender às necessidades nutricionais de leitões dos 15 aos $30 \mathrm{~kg}$ de peso vivo, de acordo com Rostagno et al. (2005), totalizando sete tratamentos com seis repetições e dois animais por unidade experimental. O critério para a formação dos blocos foi a época de início do experimento.

As rações foram formuladas à base de milho, farelo de soja, leite em pó modificado e amido de mandioca e 
suplementadas com vitaminas e minerais. Os níveis de $0,54 \%$ de Ca e $0,28 \%$ de $\mathrm{Pd}$ representaram redução de $25 \%$ de $\mathrm{Ca}$ e $30 \%$ de Pd. Para cálculo dos teores de energia metabolizável e proteína bruta das rações, não foram considerados os valores protéico e energético dos aminoácidos (Tabela 1).

As rações experimentais e a água foram fornecidas à vontade. A ração fornecida e os desperdícios foram pesados diariamente para determinação do consumo de ração e cálculo da conversão alimentar. Os animais foram pesados no início e ao final do experimento para avaliação do ganho de peso. Um grupo adicional de três leitões com $14,7 \pm 1,43 \mathrm{~kg}$ de peso corporal foi abatido para determinação da composição da carcaça ao início do experimento e posterior determinação das taxas de deposição de proteína e gordura, conforme descrito por Oliveira et al. (2005).
As análises de matéria seca, proteína e gordura das amostras foram realizadas de acordo com o método descrito por AOAC (1990), no Laboratório de Pesquisa Animal do Departamento de Zootecnia da Universidade Federal de Lavras. As coletas das amostras de sangue foram realizadas após as pesagens dos animais, sem jejum, segundo indicações de Cai et al. (1994), no período de 9 às 10h30, por meio de punção no Sinus orbital, no final do experimento. As amostras, em torno de $10 \mathrm{~mL}$ de sangue, foram centrifugadas em seguida por 10 minutos para retirada do soro. Os tubos com soro foram identificados e armazenados a $-20^{\circ} \mathrm{C}$ para posterior análise de uréia no soro sanguíneo pelo Centro de Pesquisas, Desenvolvimento, Análises Clínicas e Patologia Ltda, localizado em Lavras, Minas Gerais.

Após a coleta de sangue, os animais foram submetidos a jejum alimentar de 24 horas e um animal de cada unidade experimental foi abatido por dessensibilização por choque

Tabela 1 - Composição percentual das rações experimentais

\begin{tabular}{|c|c|c|c|c|c|c|c|}
\hline \multirow[t]{4}{*}{ Ingrediente } & \multicolumn{7}{|c|}{ Energia metabolizável (kcal/kg) } \\
\hline & \multicolumn{2}{|c|}{3.080} & \multicolumn{2}{|c|}{3.230} & \multicolumn{2}{|c|}{3.380} & \multirow[t]{2}{*}{3.230} \\
\hline & \multicolumn{6}{|c|}{ Proteína bruta (\%) } & \\
\hline & 14 & 16 & 14 & 16 & 14 & 16 & 18 \\
\hline Milho & 53,50 & 53,50 & 53,50 & 53,50 & 53,50 & 53,50 & 53,50 \\
\hline Farelo de soja & 18,90 & 23,30 & 18,90 & 23,30 & 18,90 & 23,30 & 27,80 \\
\hline Óleo de soja & 0,40 & 0,40 & 1,20 & 1,20 & 3,60 & 3,60 & 1,00 \\
\hline Leite em pó modificado & 10,00 & 10,00 & 10,00 & 10,00 & 10,00 & 10,00 & 10,00 \\
\hline Amido de mandioca & 10,10 & 6,10 & 12,50 & 8,50 & 11,00 & 7,00 & 4,50 \\
\hline Fosfato bicálcio & 0,74 & 0,70 & 0,74 & 0,70 & 0,74 & 0,70 & 1,30 \\
\hline Calcáreo calcítico & 0,59 & 0,59 & 0,59 & 0,59 & 0,59 & 0,59 & 0,65 \\
\hline Sal iodado & 0,33 & 0,33 & 0,33 & 0,33 & 0,33 & 0,33 & 0,33 \\
\hline Premix vitamínico ${ }^{1}$ & 0,10 & 0,10 & 0,10 & 0,10 & 0,10 & 0,10 & 0,10 \\
\hline Premix mineral ${ }^{2}$ & 0,10 & 0,10 & 0,10 & 0,10 & 0,10 & 0,10 & 0,10 \\
\hline L-lisina - $\mathrm{HCl} 78 \%$ & 0,47 & 0,31 & 0,47 & 0,31 & 0,47 & 0,31 & 0,14 \\
\hline DL-metionina & 0,07 & 0,04 & 0,07 & 0,04 & 0,07 & 0,04 & 0,02 \\
\hline L-treonina & 0,13 & 0,07 & 0,13 & 0,07 & 0,13 & 0,07 & 0,00 \\
\hline L-triptofano & 0,02 & 0,00 & 0,02 & 0,00 & 0,02 & 0,00 & 0,00 \\
\hline L-valina & 0,08 & 0,00 & 0,08 & 0,00 & 0,08 & 0,00 & 0,00 \\
\hline Antibiótico ${ }^{3}$ & 0,04 & 0,04 & 0,04 & 0,04 & 0,04 & 0,04 & 0,04 \\
\hline Fitase & 0,01 & 0,01 & 0,01 & 0,01 & 0,01 & 0,01 & 0,00 \\
\hline Areia lavada & 4,40 & 4,40 & 1,20 & 1,20 & 0,30 & 0,30 & 0,51 \\
\hline Total & 100 & 100 & 100 & 100 & 100 & 100 & 100 \\
\hline \multicolumn{8}{|l|}{ Composição calculada } \\
\hline Cálcio (\%) & 0,54 & 0,54 & 0,54 & 0,54 & 0,54 & 0,54 & 0,73 \\
\hline Fósforo disponível (\%) & 0,28 & 0,28 & 0,28 & 0,28 & 0,28 & 0,28 & 0,40 \\
\hline Lisina disponível $(\%)$ & 1,00 & 1,00 & 1,00 & 1,00 & 1,00 & 1,00 & 1,00 \\
\hline Metionina disponível (\%) & 0,28 & 0,28 & 0,28 & 0,28 & 0,28 & 0,28 & 0,28 \\
\hline Triptofano disponível (\%) & 0,17 & 0,17 & 0,17 & 0,17 & 0,17 & 0,17 & 0,20 \\
\hline Treonina disponível (\%) & 0,63 & 0,63 & 0,63 & 0,63 & 0,63 & 0,63 & 0,63 \\
\hline Valina disponível (\%) & 0,69 & 0,69 & 0,69 & 0,69 & 0,69 & 0,69 & 0,78 \\
\hline BED $(\mathrm{Na}+\mathrm{K}+\mathrm{Cl})^{2}$ & 154 & 175 & 154 & 175 & 154 & 175 & 196 \\
\hline
\end{tabular}

${ }^{1}$ Premix vitamínico contendo, por kg do produto: vit. A - 12.000.000 UI; vit. D3 - 1.800.000 UI; vit. E - 35 g; vit. K3 - 4 g; vit. B1 - 2,5 g; riboflavina (B2) $5 \mathrm{~g}$; piridoxina (B6) - $3 \mathrm{~g}$; vit. B12 - $30 \mathrm{mg}$; niacina - $30 \mathrm{~g}$; ácido pantotênico - $15 \mathrm{~g}$; ácido fólico - 0,8 g; biotina - 0,1 g; vit. C - $100 \mathrm{~g}$; antioxidante $125 \mathrm{mg}$; excipiente q.s.q. - $1.000 \mathrm{~g}$.

2 Premix mineral contendo, por kg do produto: Se - 500 mg; Fe - 70 g; Cu - 20 g; Mn - 40 g; Zn - 80 g; I - 0,8 g; Co - 0,5 g; excipiente q.s.q. - 1.000 g.

3 Princípio ativo tilosina + sulfametazina. 
elétrico e sangramento. Após o abate, procedeu-se à toalete e à evisceração para retirada dos órgãos. O fígado, os rins, o intestino delgado e o estômago foram pendurados à sombra por aproximadamente 20 minutos para que o sangue escorresse e, em seguida, foram pesados.

As carcaças inteiras evisceradas e sem sangue, incluindo cabeça e pés, foram pesadas e trituradas em cutter comercial de $30 \mathrm{HP}$ e $1.775 \mathrm{rpm}$ por cinco vezes. Após homogeneização, retiraram-se amostras, que foram armazenadas em congelador a $-12^{\circ} \mathrm{C}$. Ao preparar as amostras para análises laboratoriais, em virtude da alta concentração de gordura do material, procedeu-se à pré-secagem em estufa com ventilação forçada, a $60^{\circ} \mathrm{C}$, por 72 horas. Em seguida, realizou-se o pré-desengorduramento pelo método a quente em aparelho extrator do tipo Soxhlet, por 4 horas, para posterior a moagem do material. As amostras pré-secas e pré-desengorduradas foram moídas e acondicionadas em vidros para análises laboratoriais. Para correção dos valores das análises subseqüentes, foram consideradas a água e a gordura retiradas no preparo das amostras.

As análises estatísticas foram realizadas utilizando-se o programa estatístico SISVAR (Sistema para Análise de Variância de dados balanceados), desenvolvido por Ferreira (2000). Efetuou-se análise de variância global, com todos os tratamentos, a fim de se obter o quadrado médio do resíduo para testar o fatorial e realizar o teste Dunnet a 5\%, comparando-se o tratamento controle a cada um dos tratamentos. Utilizou-se o teste Student-NewmanKeuls (SNK) a 5\% de probabilidade para testar os tratamentos no esquema fatorial.

\section{Resultados e Discussão}

Com relação às variáveis de desempenho e teor de uréia no sangue, não houve efeito da interação níveis de EM× níveis de $\mathrm{PB}$ das rações formuladas com base no conceito de proteína ideal e fitase (Tabela 2). Entretanto, houve efeito significativo $(\mathrm{P}<0,05)$ do nível de EM sobre o consumo médio diário de ração. Assim, os resultados deste experimento confirmam os obtidos por Dividich \& Noblet (1986) e Oliveira et al. (1997 b), que avaliaram rações com diversos níveis de energia digestível para leitões e observaram que a quantidade de alimento consumida varia conforme a exigência de energia do animal.

$\mathrm{O}$ adequado balanço de aminoácidos favorece a síntese protéica, de modo que ocorre menor catabolismo de aminoácidos e menor síntese de uréia, principal produto deste catabolismo. Portanto, os níveis similares de uréia no soro sanguíneo entre os tratamentos comprovam que o balanço de aminoácidos foi semelhante entre as rações e que o aumento dos níveis de energia das rações não influenciou a utilização de aminoácidos pelos leitões.

Resultados de uréia semelhantes foram obtidos por Zangeronimo (2006), que não verificou diferenças significativas no teor de uréia ao trabalhar com níveis de 16 e $18 \%$ de $\mathrm{PB}$ em rações contendo lisina, metionina e treonina, formuladas segundo o conceito de proteína ideal. Oliveira et al. (2005) constataram que os teores de uréia plasmática não foram influenciados pelos níveis de EM.Sobre o uso de fitase, Silva et al. (2004) observaram que a utilização de fitase em rações para suínos em crescimento diminuiu o teor

Tabela 2 - Ganho de peso médio diário, consumo de ração médio diário, conversão alimentar e teor de uréia no soro de leitões dos 15 aos $35 \mathrm{~kg}$ alimentados com rações com diferentes níveis de energia metabolizável e proteína bruta, formuladas segundo o conceito de proteína ideal e fitase

\begin{tabular}{|c|c|c|c|c|}
\hline & \multirow[t]{2}{*}{$\begin{array}{c}\text { Energia } \\
\text { metabolizável }\end{array}$} & \multicolumn{2}{|c|}{$\begin{array}{l}\text { Proteína } \\
\text { bruta (\%) }\end{array}$} & \multirow[t]{2}{*}{ Média $^{1}$} \\
\hline & & 14 & 16 & \\
\hline \multirow{6}{*}{$\begin{array}{l}\text { Ganho de peso } \\
\text { médio diário }(\mathrm{g} / \mathrm{dia})\end{array}$} & 3.080 & 679 & 679 & 679 \\
\hline & 3.230 & 672 & 654 & 663 \\
\hline & 3.380 & 638 & 662 & 650 \\
\hline & Média & 663 & 665 & \\
\hline & Controle & 627 & & \\
\hline & $\mathrm{CV}(\%)$ & 7,57 & & \\
\hline \multirow{6}{*}{$\begin{array}{l}\text { Consumo médio } \\
\text { diário de ração }(\mathrm{g} / \mathrm{dia})\end{array}$} & 3.080 & 1.366 & 1351 & $1.358 \mathrm{a}$ \\
\hline & 3.230 & 1.327 & 1.296 & $1.311 \mathrm{ab}$ \\
\hline & 3.380 & 1.226 & 1.267 & $1.246 \mathrm{~b}$ \\
\hline & Média & 1.306 & 1.305 & \\
\hline & Controle & 1.249 & & \\
\hline & $\mathrm{CV}(\%)$ & 6,65 & & \\
\hline \multirow[t]{6}{*}{ Conversão alimentar } & 3.080 & 2,01 & 1,99 & 2,00 \\
\hline & 3.230 & 1,98 & 1,98 & 1,98 \\
\hline & 3.380 & 1,92 & 1,91 & 1,91 \\
\hline & Média & 1,97 & 1,96 & \\
\hline & Controle & 2,00 & & \\
\hline & $\mathrm{CV}(\%)$ & 6,03 & & \\
\hline \multirow[t]{6}{*}{ Uréia (mg/dL) } & 3.080 & $23,67 *$ & $23,50^{*}$ & 23,58 \\
\hline & 3.230 & $23,33 *$ & $23,17 *$ & 23,55 \\
\hline & 3.380 & $22,50 *$ & $23,83^{*}$ & 23,17 \\
\hline & Média & 23,17 & 23,5 & \\
\hline & Controle & 30 & & \\
\hline & $\mathrm{CV}(\%)$ & 9,56 & & \\
\hline
\end{tabular}

* Médias diferem $(P<0,05)$ do tratamento controle pelo teste Dunnet. ${ }^{1}$ Médias seguidas por letras distintas diferem $(P<0,05)$ pelo teste SNK. CV - coeficiente de variação. 
de uréia no plasma, confirmando a hipótese de que esta enzima pode estar também relacionada à maior disponibilidade de aminoácidos dietéticos.

Na comparação das médias de cada combinação do nível de EM e PB com o tratamento controle, verificou-se que o teor de uréia foi significativamente influenciado $(\mathrm{P}<0,05)$ pelos níveis de EM e PB das rações formuladas segundo o conceito de proteína ideal e fitase, no entanto, as características de desempenho não apresentaram diferenças significativas $(\mathrm{P}>0,05)$. Os leitões alimentados com as rações com diferentes níveis de EM e PB, formuladas com base no conceito de proteína ideal e fitase e com melhor balanço de aminoácidos, por apresentarem menor nível de uréia no soro, tiveram maior síntese de proteína em nível celular e menor catabolismo de aminoácidos.

Resultados semelhantes foram encontrados por Figueroa et al. (2002). Kerr et al.(2003 a,b), em experimento com animais em crescimento, verificaram que rações com baixa proteína bruta suplementadas com aminoácidos es senciais resultaram em menor concentração de uréia no sangue. Walz \& Pallauf (2002) constataram que, para suínos em crescimento, rações com níveis reduzidos de $\mathrm{PB}, \mathrm{Pd}$ e Ca suplementadas com aminoácidos sintéticos e fitase reduziram em $35 \%$ o nível de uréia plasmática em comparação àquelas formuladas com os níveis de $\mathrm{PB}, \mathrm{Pd}$ e Ca recomendados e sem suplementação de aminoácidos sintéticos.

Não houve influência significativa $(\mathrm{P}>0,05)$ das interação níveis de $\mathrm{EM} \times$ níveis de $\mathrm{PB}$ sobre os consumos de energia metabolizável e nitrogênio $(\mathrm{N})$ e a eficiência de utilização do nitrogênio para ganho (Tabela 3). O nível de $\mathrm{PB}$, no entanto, influenciou significativamente $(\mathrm{P}<0,01) \mathrm{o}$ consumo de nitrogênio e eficiência de utilização do nitrogênio para ganho.

Apesar de o ganho de peso médio diário e a conversão alimentar não terem sido influenciados significativamente ( $\mathrm{P}>0,05)$ pelos tratamentos, o aumento do consumo de ração não resultou em diferença significativa no consumo de EM, evidenciando que os animais consumiram alimento para atender às suas necessidades de energia para mantença e crescimento, fato relacionado à semelhança no ganho de peso e no consumo de EM entre os tratamentos. Entretanto, os resultados deste experimento diferiram dos obtidos por Oliveira et al. (2005), que, ao reduzirem os níveis de PB da ração, não observaram diferença significativa na eficiência de utilização do nitrogênio para ganho.

Na comparação das médias de cada combinação dos níveis de EM e PB ao tratamento controle, verificou-se que o consumo de nitrogênio e a eficiência de utilização do nitrogênio para ganho foram significativamente influ enciados $(\mathrm{P}<0,05)$ pelas rações. Os leitões que consumiram as
Tabela 3 - Consumos diários de energia metabolizável 290 (CEM) e nitrogênio $(\mathrm{CN})$ e eficiência de utilização de nitrogênio para ganho (EUNG) em leitões dos 15 aos $35 \mathrm{~kg}$ alimentados com rações contendo diferentes níveis de energia metabolizável e proteína bruta, formuladas segundo o conceito de proteína ideal e fitase

\begin{tabular}{|c|c|c|c|c|}
\hline & \multirow[t]{2}{*}{$\begin{array}{c}\text { Energia } \\
\text { metabolizável }\end{array}$} & \multicolumn{2}{|c|}{$\begin{array}{l}\text { Proteína } \\
\text { bruta }(\%)\end{array}$} & \multirow[t]{2}{*}{ Média } \\
\hline & & 14 & 16 & \\
\hline \multirow{6}{*}{$\begin{array}{l}\text { Consumo de } \\
\text { EM (g/dia) }\end{array}$} & 3.080 & 4.206 & 4.160 & 4.183 \\
\hline & 3.230 & 4.285 & 4.187 & 4.236 \\
\hline & 3.380 & 4.143 & 4.281 & 4.212 \\
\hline & Média & 4.211 & 4.209 & \\
\hline & Controle & 4.033 & & \\
\hline & $\mathrm{CV}(\%)$ & 6,75 & & \\
\hline \multirow{6}{*}{ Consumo de N (g/dia) } & 3.080 & $30,9 *$ & $33,3 *$ & 32,1 \\
\hline & 3.230 & $30,0 *$ & $33,5^{*}$ & 31,7 \\
\hline & 3.380 & $27,7 *$ & $32,7 *$ & 30,2 \\
\hline & Média & $29,5 \mathrm{~A}$ & $33,2 \mathrm{~B}$ & \\
\hline & Controle & 37,2 & & \\
\hline & $\mathrm{CV}(\%)$ & 6,21 & & \\
\hline \multirow{6}{*}{$\begin{array}{l}\text { Eficiência de utilização } \\
\text { de N para ganho } \\
(\mathrm{g} \mathrm{GP} / \mathrm{g} \mathrm{N})^{2}\end{array}$} & 3.080 & $22,2 *$ & $20,5^{*}$ & 21,3 \\
\hline & 3.230 & $22,5^{*}$ & $19,6^{*}$ & 21,0 \\
\hline & 3.380 & $23,2 *$ & $20,3^{*}$ & 21,7 \\
\hline & Média & $22,6 \mathrm{~A}$ & $20,1 \mathrm{~B}$ & \\
\hline & Controle & 16,9 & & \\
\hline & $\mathrm{CV}(\%)$ & 7,2 & & \\
\hline
\end{tabular}

${ }_{1}^{1}$ Médias diferem $(P<0,01)$ pelo teste $F$.

$2 \mathrm{~g} \mathrm{GP} / \mathrm{g} \mathrm{N}=$ grama de ganho de peso por grama de nitrogênio consumido. * Médias diferem $(P<0,05)$ do tratamento controle pelo teste Dunnet.

CV - coeficiente de variação.

rações com diferentes níveis de $\mathrm{EM}$ e $\mathrm{PB}$, formuladas segundo o conceito proteína ideal e fitase, apresentaram menor consumo de nitrogênio e maior eficiência de utilização de nitrogênio para ganho se comparados àqueles alimentados com a ração controle. Os animais que consumiram as rações com diferentes níveis de EM formuladas com níveis reduzidos de proteína bruta, cálcio, fósforo disponível e suplementadas com fitase apresentaram ainda desempenho semelhante ao daqueles alimentados com a ração controle com níveis de EM, PB, Ca e Pd recomendados porRostagno et al. (2005) e sem adição de fitase.

Considerando esses resultados, pode-se inferir que a redução de proteína bruta da ração com a suplementação de aminoácidos sintéticos essenciais segundo o conceito de proteína ideal melhora a eficiência de utilização do nitrogênio da ração, por reduzir o excesso de aminoácidos fornecidos aos animais, e não compromete o desempenho dosanimais. Esses resultados estão de acordo com os relatados por Ferreira et al. (2003), que observaram aumento no consumo 
de nitrogênio e redução na eficiência de utilização de nitrogênio para ganho à medida que os níveis de $\mathrm{PB}$ foram aumentados de 14 para $18 \%$.

Nesta pesquisa, a suplementação com aminoácidos sintéticos e fitase em rações com níveis diferentes de EM e PB e níveis reduzidos de cálcio e fósforo disponível proporcionou aos leitões desempenho semelhante ao obtido com a ração controle, formulada com base na proteína bruta, sem adição de fitase, e com níveis de EM, PB, Pd e Ca de acordo com as recomendações de Rostagno et al. (2005). Es te resultado pode ser atribuído a dois fatores: animais alimentados com rações com nível reduzido de PB, com aplicação do conceito de proteína ideal e suplementação de aminoácidos sintéticos consumiram rações com adequada relação dos aminoácidos essenciais; ou a fitase causou hidrólise do ácido fítico, liberando fósforo, cálcio e outros minerais, que podem ter se complexado ao ácido fítico, tornando-se disponíveis para o metabolismo.

Walz \& Pallauf (2002), em experimento com suínos em crescimento, verificaram que rações com níveis reduzidos de $\mathrm{PB}, \mathrm{Pd}$ e Ca combinados à suplementação de aminoácidos sintéticos e fitase promoveram desempenho, consumo de energia metabolizável e utilização de energia para ganho semelhantes. Além disso, Ludke et al. (2000) observaram que, ao incluírem fitase nas rações, o desempenho dos leitões melhorou e que a enzima foi mais eficaz nas dietas com 16\% PB em comparação a uma ração com 18\% PB.

Não houve efeito $(\mathrm{P}>0,05)$ da interação níveis de $\mathrm{EM} \times$ níveis de $\mathrm{PB}$ sobre as taxas de deposição de proteína e gordura na carcaça. Os níveis de EM e PB não influenciaram $(\mathrm{P}>0,05)$ a taxa de deposição de proteína (Tabela 4), entretanto, houve efeito do nível de EM $(\mathrm{P}<0,01)$ sobre a taxa de deposição de gordura (Tabela 4). A taxa de deposição de proteína não foi afetada pelos níveis de EM e PB da ração, comprovando que a ingestão diária atendeu às demandas metabólicas para deposição de proteína dos animais e que a retenção de nitrogênio não foi comprometida pela redução do nível de PB.

Os resultados deste experimento foram semelhantes aos encontrados por Ferreira et al. (2003,2006), que não constataram efeito da redução do nível de $\mathrm{PB}$ da ração sobre a taxa de deposição de proteína dos leitões. Oliveira et al. (2005) não encontraram diferenças significativas na taxa de deposição de proteína em leitões alimentados com rações com níveis crescentes de energia metabolizável, formuladas com base no conceito da proteína ideal. Por outro lado, esses resultados contrastam com aqueles obtidos Shelton et al. (2003), que observaram que a deposição de proteína foi maior em suínos em crescimento alimentados com rações de maior nível energético.
Tabela 4 - Taxas de deposição de proteína e gordura da carcaça de leitões aos $35 \mathrm{~kg}$ alimentados com rações com diferentes níveis de energia metabolizável e proteína bruta, formuladas segundo o conceito de proteína ideal e fitase $e^{1}$

\begin{tabular}{lcccc}
\hline & $\begin{array}{c}\text { Energia } \\
\text { metabolizável }\end{array}$ & \multicolumn{2}{c}{$\begin{array}{c}\text { Proteína } \\
\text { bruta }(\%)\end{array}$} & \multirow{2}{*}{ Média $^{1}$} \\
\cline { 2 - 4 } & & 14 & 16 & \\
\hline Taxa de deposição & 3.080 & 97 & 94 & 96 \\
de proteína & 3.230 & 92 & 92 & 92 \\
& 3.380 & 93 & 93 & 93 \\
\cline { 2 - 4 } & Média & 94 & 93 & \\
\cline { 2 - 4 } & Controle & 87 & & \\
\cline { 2 - 4 } de gordura & CV $(\%)$ & 8,4 & & \\
\hline Taxa de deposição & 3.080 & 91 & 91 & $91 \mathrm{a}$ \\
& 3.230 & 98 & 100 & $99 \mathrm{a}$ \\
& 3.380 & 115 & 113 & $114 \mathrm{~b}$ \\
\cline { 2 - 4 } & Média & 101 & 101 & \\
\cline { 2 - 4 } & Controle & 92 & & \\
\cline { 2 - 4 } & CV $(\%)$ & 16,36 & & \\
\hline
\end{tabular}

${ }^{1}$ Médias não diferem $(P>0,05)$ pelo teste Dunnet.

2 Médias seguidas por letras distintas diferem $(P<0,05)$ pelo teste SNK. CV - coeficiente de variação.

A taxa de deposição de gordura na carcaça dos leitões foi maior $(\mathrm{P}<0,05)$ no nível de $3.380 \mathrm{kcal}$, o que provavelmente está relacionado ao menor suporte energético proporcionado pelas rações com níveis crescentes de óleo, uma vez que não houve diferença no consumo de energia. Esses resultados foram semelhantes aos obtidos por Donzele et al. (1997), Ferreira et al. (1998) e Oliveira et al. (2005), que observaram aumento linear na taxa de deposição de gordura com o aumento dos níveis de EM em rações formuladas com base no conceito de proteína ideal para suínos em crescimento.

Comparando as médias pelo teste Dunnet, observou-se que não houve diferença $(\mathrm{P}>0,05)$ para as taxas de deposição de proteína e gordura entre as rações experimentais e o tratamento controle. Kerr et al. (2003a) e Le Bellego et al. (2002) não observaram diferenças nas taxas de deposição de proteína e gordura da carcaça de leitões com a redução do nível de PB da ração. Desse modo, a redução de até quatro unidades percentuais no teor de proteína de rações para suínos em crescimento não provoca alterações na concentração de proteína e lipídios da carcaça, desde que as rações sejam suplementadas com os principais aminoácidos limitantes.

Os resultados de peso absoluto e relativo do fígado, dos rins, do intestino delgado e do estômago dos leitões aos $35 \mathrm{~kg}$ não foram influenciados significativamente $(\mathrm{P}>0,05)$ pela interação níveis de $\mathrm{EM} \times$ níveis de $\mathrm{PB}$ das 
rações formuladas com base na proteína ideal, suplementadas com aminoácidos sintéticos e fitase (Tabelas 5 e 6 ).Também não foram observados efeitos $(\mathrm{P}>0,05)$ do nível de energia metabolizável e do teor de proteína bruta sobre estas variáveis.

Rao \& Mccraken (1992) e Bikker et al. (1995) observaram redução no tamanho dos órgãos apenas quando a variação na ingestão de energia foi superior a $15 \%$. De modo geral, os resultados quanto à variação dos pesos de órgãos são controversos em vários estudos, pois essas diferenças entre os trabalhos podem estar relacionadas aos níveis de energia e proteína utilizados, à temperatura ambiente e ao período experimental, que podem não ter sido suficientes para denotar quaisquer diferenças entre os pesos dos órgãos.

Tabela 5 - Peso do fígado, dos rins, do intestino delgado e do estômago de leitões aos $35 \mathrm{~kg}$ alimentados com rações com diferentes níveis de energia metabolizável e proteína bruta, formuladas segundo o conceito de proteína ideal e fitase ${ }^{1,2}$

\begin{tabular}{|c|c|c|c|c|}
\hline & \multirow[t]{2}{*}{$\begin{array}{c}\text { Energia } \\
\text { metabolizável }\end{array}$} & \multicolumn{2}{|c|}{$\begin{array}{l}\text { Proteína } \\
\text { bruta (\%) }\end{array}$} & \multirow[t]{2}{*}{ Média $^{1}$} \\
\hline & & 14 & 16 & \\
\hline \multirow[t]{6}{*}{ Fígado (g) } & 3.080 & 874 & 918 & 896 \\
\hline & 3.230 & 901 & 902 & 901 \\
\hline & 3.380 & 888 & 852 & 870 \\
\hline & Média & 888 & 891 & \\
\hline & Controle & 898 & & \\
\hline & $\mathrm{CV}(\%)$ & 12,59 & & \\
\hline \multirow[t]{6}{*}{ Rins (g) } & 3.080 & 148 & 143 & 145 \\
\hline & 3.230 & 143 & 137 & 140 \\
\hline & 3.380 & 133 & 146 & 139 \\
\hline & Média & 142 & 142 & \\
\hline & Controle & 142 & & \\
\hline & $\mathrm{CV}(\%)$ & 13,15 & & \\
\hline \multirow[t]{6}{*}{ Intestino delgado $(\mathrm{g})$} & 3.080 & 1.035 & 1.015 & 1.025 \\
\hline & 3.230 & 1.030 & 993 & 1.011 \\
\hline & 3.380 & 1.043 & 1.049 & 1.046 \\
\hline & Média & 1.009 & 1.000 & \\
\hline & Controle & 1.036 & & \\
\hline & $\mathrm{CV}(\%)$ & 8,22 & & \\
\hline \multirow[t]{6}{*}{ Estômago (g) } & 3.080 & 214 & 200 & 207 \\
\hline & 3.230 & 202 & 213 & 207 \\
\hline & 3.380 & 206 & 216 & 211 \\
\hline & Média & 207 & 210 & \\
\hline & Controle & 193 & & \\
\hline & $\mathrm{CV}(\%)$ & 8,54 & & \\
\hline
\end{tabular}

1 Médias não diferem $(P>0,05)$ pelo teste $F$.

${ }^{2}$ Médias não diferem $(P>0,05)$ do tratamento controle pelo teste Dunnet. CV - coeficiente de variação.
Tabela 6 - Peso relativo (\% da carcaça) de fígado, rins, intestino delgado e estômago de leitões aos $35 \mathrm{~kg}$ alimentados com rações com diferentes níveis de energia metabolizável e proteína bruta, formuladas segundo o conceito de proteína ideal e fitase ${ }^{1,2}$

\begin{tabular}{|c|c|c|c|c|}
\hline & \multirow[t]{2}{*}{$\begin{array}{c}\text { Energia } \\
\text { metabolizável }\end{array}$} & \multicolumn{2}{|c|}{$\begin{array}{c}\text { Proteína } \\
\text { bruta }(\%)\end{array}$} & \multirow[t]{2}{*}{ Média } \\
\hline & & 14 & 16 & \\
\hline \multirow[t]{6}{*}{ Fígado (\%) } & 3.080 & 3,39 & 3,68 & 3,53 \\
\hline & 3.230 & 3,65 & 3,64 & 3,64 \\
\hline & 3.380 & 3,64 & 3,49 & 3,56 \\
\hline & Média & 3,56 & 3,60 & \\
\hline & Controle & 3,86 & & \\
\hline & $\mathrm{CV}(\%)$ & 10,77 & & \\
\hline \multirow[t]{6}{*}{ Rins (\%) } & 3.080 & 0,57 & 0,57 & 0,57 \\
\hline & 3.230 & 0,58 & 0,55 & 0,56 \\
\hline & 3.380 & 0,54 & 0,60 & 0,57 \\
\hline & Média & 0,56 & 0,57 & \\
\hline & Controle & 0,61 & & \\
\hline & $\mathrm{CV}(\%)$ & 12,28 & & \\
\hline \multirow[t]{6}{*}{ Intestino delgado (\%) } & 3.080 & 4,03 & 4,09 & 4,06 \\
\hline & 3.230 & 4,19 & 4,02 & 4,10 \\
\hline & 3.380 & 4,33 & 4,27 & 4,30 \\
\hline & Média & 4,13 & 4,04 & \\
\hline & Controle & 4,45 & & \\
\hline & $\mathrm{CV}(\%)$ & 8,85 & & \\
\hline \multirow[t]{6}{*}{ Estômago (\%) } & 3.080 & 0,84 & 0,80 & 0,82 \\
\hline & 3.230 & 0,82 & 0,87 & 0,85 \\
\hline & 3.380 & 0,86 & 0,88 & 0,87 \\
\hline & Média & 0,84 & 0,85 & \\
\hline & Controle & 0,83 & & \\
\hline & $\mathrm{CV}(\%)$ & 9,90 & & \\
\hline
\end{tabular}

${ }^{1}$ Médias não diferem $(P>0,05)$ pelo teste $F$.

2 Médias não diferem $(P>0,05)$ do tratamento controle pelo teste Dunnet. CV - coeficiente de variação.

Os resultados deste trabalho são semelhantes aos encontrados por Oliveira et al. (2005), que observaram que os pesos absoluto e relativo de fígado e rins de leitões não foram influenciados $(\mathrm{P}>0,05)$ pelas rações contendo níveis crescentes de energia metabolizável, baseadas no conceito de proteína ideal. Oliveira et al. (1997a) também não observaram efeito dos níveis de energia digestível da dieta sobre os pesos absoluto e relativo de fígado e rins.

Zangeronimo (2006) e Ferreira et al. (2003) não observaram efeito da redução do nível de proteína bruta da ração sobre os pesos absoluto e relativo de fígado e rins. Kerr et al. (2003a) observaram que os pesos de fígado e intestino delgado de leitões de 23 a $36 \mathrm{~kg}$ não foram afetados pelas rações contendo níveis reduzidos de PB. No entanto, Ferreira et al. (2003) constataram que a redução do teorde 
proteína bruta influenciou os pesos absolutos de estômago e intestino delgado e os pesos relativos de estômago. Santiago et al. (2005) observaram aumento no peso do fígado em suínos na fase inicial alimentados com níveis crescentes de proteína bruta na ração $(17,19,21$ e $23 \%)$.

Os pesos absoluto e relativo de fígado, rins, intestino delgado e estômago dos leitões alimentados com as rações com diferentes níveis de EM e PB, formuladas com base na proteína ideal e suplementadas com aminoácidos sintéticos e fitase, não diferiram significativamente $(\mathrm{P}>0,05)$ dos obtidos com a ração controle. Esses resultados corroboram relatos de Kies et al. (2005) de que não houve diferença significativa nos pesos de intestino delgado e fígado dos leitões alimentados com as rações suplementadas com fitase. No entanto, Kerr et al. (2003a) verificaram que os animais alimentados com as dietas contendo $12 \% \mathrm{~PB}$ suplementadas com aminoácidos sintéticos tiveram menores pesos de rins e estômago.

\section{Conclusões}

A redução dos níveis de energia metabolizável, proteína bruta, cálcio e fósforo disponível para $3.080 \mathrm{kcal} \mathrm{EM} / \mathrm{kg}, 14$; 0,54 e $0,28 \%$, respectivamente, em rações formuladas segundo o conceito de proteína ideal com suplementação de fitase não prejudica o desempenho e reduz a taxa de deposição de gordura na carcaça de leitões na fase de 15 a $35 \mathrm{~kg}$.

\section{Agradecimento}

À Roche Vitaminas do Brasil, pela doação da enzima fitase para realização dos experimentos.

\section{Literatura Citada}

ADEOLA, O.; LAWRENCE, V.V.; SUTTON, A.L. et al. Phytaseinduced changes in mineral utilization in zinc supplemented diets for pigs. Journal of Animal Science, v.73, n.11, p.33843391,1995

ASSOCIATION OF OFFICIAL ANALYTICAL CHEMIST - AOAC. Official methods of analysis. 15.ed. Arlington, 1990. 1230p.

BATTERHAM, E.S. Protein and energy relationships for growing pigs. In: COLE, D.J.A.; WISEMAN, J.; VARLEY, M.A. (Eds.)Principles of pig science. Nottinghan: Redwood Books, 1994. p.107-121.

BIKKER, P.; KARABINAS, V.; VERSTEGEN, M.W.A. et al. Protein and lipid accretion in body components of growing gilts (20 to 45 kilograms) as affected by energy intake. Journal of Animal Science, v.73, n.8, p.2355-2363, 1995.

CAI, Y.; ZIMMERMAN, D.R.; EWAN, R.C. Diurnal variation in concentrations of plasma urea nitrogen and amino acids in pigs given free access to feed or fed twice daily. Journal of Nutrition, v.124, n.3, p.1088-1093, 1994.

CROMWELL, G.L.; COFFEY, R.D. Phosphorus - A key essential nutrient, yet a possible major polluant - its central role in animal nutrition. In: ALLTECH'S ANNUAL SYMPOSIUM OF
BIOTECHNOOGY IN THE FEED INDUSTRY, 7, 1991, Nicholasville. Proceedings... Nicholasville: Alltech Technical Publications, 1991. p.133-145.

CURTIS, S.E. Environmental management in animal agriculture. Ames: Iowa State University Press, 1983. 402p.

DIVIDICH, J.L.; NOBLET, J. Effect of dietary energy level on the performance of individually housed early weaned piglets in relation to environmental temperature. Livestock Production Science, v.14, n.1, p.255-263. 1986.

DONZELE, J.L.; OLIVEIRA, R.F.M.; FREITAS, R.T.F. et al. Avaliação de níveis de energia digestível para leitoas dos 15 aos $30 \mathrm{~kg}$ mantidas em ambiente de alta temperatura. Revista Brasileira de Zootecnia, v.25, n.4, p.744-752, 1997.

FERREIRA, R.A.; OLIVEIRA, R.F.M.; DONZELE, J.L. et al. Níveis de energia digestível para leitoas de 15 a $30 \mathrm{~kg}$ mantidas em ambiente frio. Revista Brasileira de Zootecnia, v.27, n.6, p.1131-1139, 1998.

FERREIRA, D.F. Análises estatísticas por meio do Sisvar para Windows versão 4. 0. In: REUNIÃO ANUAL DA REGIÃO BRASILEIRA DA SOCIEDADE INTERNACIONAL DE BIOMETRIA, 45., 2000, São Carlos. Anais... São Carlos: UFSCar, 2000. p.255-258.

FERREIRA, R.A.; OLIVEIRA, R.F.M.; DONZELE, J.L. et al. Redução de proteína bruta para suínos machos castrados dos 15 aos $30 \mathrm{~kg}$ mantidos em termoneutralidade. Revista Brasileira de Zootecnia, v.32, n.6, p.1639-1646, 2003.

FERREIRA, R.A.; OLIVEIRA, R.F.M.; DONZELE, J.L. et al. Redução da proteína bruta da ração e suplementação de aminoácidos para suínos machos castrados dos 15 aos $30 \mathrm{~kg}$ mantidos em ambiente de alta temperatura. Revista Brasileira de Zootecnia, v.35, n.3, p.1056-1062, 2006 (supl.).

FIGUEROA, J.L.; LEWIS, A.J.; MILLER, P.S. et al. Nitrogen metabolism and growth performance of gilts fed standard cornsoybean meal diets or low-crude protein, amino acidsupplemented diets. Journal of Animal Science, v.80, n.11, p.2911-2919, 2002.

HEDEGUS, M. The role of feed protein quality in reducing environmental pollution by lowering nitrogen excretion. III. Strategies of feeding: a review. Acta Veterinaria Hungarica, v.44, n.2, p.153-163, 1996.

KERR, B.J.; SOUTHERN, L.L.; BIDNER, T.D. et al. Influences of dietary protein level, amino acid supplementation and e dietary energy levels on growing finishing pig performance and carcass composition. Journal of Animal Science, v.81, n.12, p.30753087, 2003a.

KERR, B.J.; YEN, B.J.; NIENABER, J.A. et al. Influences of dietary protein level, amino acid supplementation and environmental temperature on performance, body composition, organ weights and total heat production of growing pigs. Journal of Animal Science, v.81, n.8, p.1998-2007, 2003b.

KIES, A.K.; GERRITS, W.J.J.; SCHRAWA, J.W. et al. Mineral absorption and excretion as affected by microbial phytase, and their effect on energy metabolism in young piglets. Journal of Nutrition, v.135, n.3, p.1131-1138, 2005.

LE BELLEGO, L.; Van MILGEN J.; NOBLET, J. Effect of high temperature and low protein diets on performance of growing pigs. Journal of Animal Science, v. 80, n.3, p.691-701, 2002.

LUDKE, M.C.M.M.; LOPEZ, J.; BRUM, P.A.R. et al. Influência da fitase na utilização de nutrientes em dietas compostas por milho e farelo de soja para suínos em crescimento. Revista Brasileira de Zootecnia, v.29, n.5, p.1402-1413, 2000.

OLIVEIRA, R.F.M.; DONZELE, J.L.; FREITAS, R.T.F. et al. Avaliação de níveis de energia digestível para leitoas em recria mantidas em ambiente de conforto térmico. Revista Brasileira de Zootecnia, v.26, n.4, p.779-786, 1997a.

OLIVEIRA, R.F.M.; DONZELE, J.L.; FREITAS, R.T.F. et al. Níveis de energia digestível para leitões dos 15 aos $30 \mathrm{~kg}$ de peso mantidos em ambiente de conforto térmico. Revista Brasileira de Zootecnia, v.26, n.3, p.539-547, 1997b. 
OLIVEIRA, G.C.; MOREIRA, I.; FRAGA, A.L. et al. Metabolizable energy requirement for starting barrow pigs (15 to $30 \mathrm{~kg}$ ) fed on the ideal protein concept based diets. Brazilian Archives of Biology and Technology, v.48, n.5, p.729-737, 2005.

POZZA, P.C.; GOMES, P.C.; DONZELE, J.L. Exigência de treonina digestível para suínos machos castrados dos 15 aos $30 \mathrm{~kg}$. Revista Brasileira de Zootecnia, v.28, p.560-568, 1999.

RAO, D.S.; McCRACKEN, K.J. Energy: protein interactions in growing boars on high genetic potential for lean growth. 1. Effects on growth, carcass characteristics and organ weights. Animal Production, v.54, n.1, p.75-82, 1992

REZENDE, W.O.; DONZELE, J.L.; OLIVEIRA, R.F.M. et al. Níveis de energia metabolizável mantendo a relação lisina digestível:caloria em rações para suínos machos castrados em terminação. Revista Brasileira de Zootecnia, v.35, n.3, p.1101-1106, 2006 (supl.).

ROSTAGNO, H.S.; ALBINO, L.F.T.; DONZELE, J.L. et al. Tabelas brasileiras para aves e suínos: composição de alimentos e exigências nutricionais. 2.ed. Viçosa: Editora UFV, 2005. 186p.

SANTIAGO, A.L.S.; CARVALHO, L.E.; BASTOS, F.J.S. et al. Estudo de níveis protéicos crescentes sobre o peso corporal, peso da carcaça e órgãos de leitões de creche. In: CONGRESSO BRASILEIRO DE VETERINÁRIOS ESPECIALISTAS EM
SUÍNOS, 12., 2005, Fortaleza. Anais... Fortaleza: ABRAVES, 2005. (CD-ROM).

SILVA, H.O.; FIALHO, E.T.; FREITAS, R.T.F. et al. Phytase in rations of growing pigs: performance, blood parameters and bone mineral content. Ciência e Agrotecnologia, v.28, n.6, p.1428-1436, 2004.

SHELTON, J.L.; SOUTHERN, L.L.; BIDNER, T.D. et al. Effect of microbial phytase on energy availability, and lipid and protein deposition in growing swine. Journal of Animal Science, v.82, n.8, p.2053-2062, 2003.

WALZ, J.; PALLAUF, M. Microbial phytase combined with amino acid supplementation reduces $\mathrm{P}$ and $\mathrm{N}$ excretion of growing and finishing pigs without less of performance. International Journal of Food Science and Technology, v.37, n.7, p.835$848,2002$.

ZANGERONIMO, M.G. Níveis de lisina digestível em rações para leitões de 9 a 25 kg. Lavras: Universidade Federal de Lavras, 2006. 95p. Tese (Doutorado em Zootecnia) Universidade Federal de Lavras, 2006.

ZANGERONIMO, M.G.; FIALHO E.T.; LIMA, J.A. et al. Redução do nível de proteína bruta da ração com suplementação de aminoácidos sintéticos para leitões na fase inicial. Revista Brasileira de Zootecnia, v.35, n.3, p.849-856, 2006. 